\title{
O JOGO DOS MARCADORES PESSOAIS EM GUATÓ
}

\section{Adair P. Palácio \\ Universidade Federal de Pernambucol Universidade Federal de Alagoas}

Guató $^{1}$ : pronomes, nomes e verbos.

\section{Flexão pronominal}

Os pronomes pessoais são constituidos pelos morfemas raizes pronominais 'ó'. para o singular, e 'óko', para o plural, e por afixos flexionais que representam as pessoas. No singular, a flexão realiza-se pelos sufixos '-yo' "eu" e '-he' "tu,você"; e no plural, pelos prefixos 'gi-' "nós" (eu e tu/vocês), primeira pessoa dual, e 'hadji-' "nós" (eu e outro(s) e ocasionalmente tu), primeira pessoa plural, conforme a seguinte tabela:

\section{Tabela 1}

$\begin{array}{lllll}\text { Pessoa } & \text { Prefixo } & \text { Raiz } & \text { Sufixo } & \text { Glossa } \\ 1 & & \text { ó } & \text {-jo } & \text { "eu" } \\ 2 & & \text { ó } & \text {-he } & \text { "tu" } \\ 1 \mathrm{~d} & \text { gi- } & \text { óko } & & \text { "nós" }(1+2) \\ 1 \mathrm{p} & \text { hadzi- } & \text { óko } & & \text { "nós" }(1+3+(2))\end{array}$

Guató é a língua falada pelos indios do mesmo nome, de MS, às margens do rio Paraguai. Os dados da língua foram coletados entre $75-84 \mathrm{e}$ serviram de base para a descriçào da lingua. na tese: Guató, a língua dos indios canociros do rio Paraguai, apresentada ao IEL, UNICAMP, em 1984. Na época o grupo era constituido por aproximadamente 200 pessoas, mas apenas umas 20 falavam a língua. Trata-se de uma língua tonal (tom alto - representado aqui pelo acento tônico - e tom baixo, não representado graficamente). A acentuação é irrelevante fonologicamente $e$ não está aqui representada. As abreviações significam: ind (indicativo), det (determinante) e o (morfema zero). 
O prefixo de primeira pessoa dual, 'gi-', perde a vogal ao juntar-se ao tema pronominal: 'góko' "nós". Este é um processo morfofonológico muito recorrente na língua.

Há duas maneiras de expressar o plural da segunda pessoa, pospondo-se ao pronome ou à raiz a partícula pluralizadora 'mẽhẽ' : 'óhe mẽhẽ' ou 'ó mẽhẽ' "vocês".

\section{Flexão nominal}

A flexão pessoal dos nomes tem valor semântico de posse, caso possessivo, e se realiza por prefixos, exceto a primeira pessoa do singular, que é um prefixo e um sufixo simultâneos, segundo a tabela:

\section{Tabela 2}

$\begin{array}{llll}\text { Pessoa } & \text { Prefixo } & \text { Sufixo } & \text { Glossa } \\ 1 & \text { a- } & \text {-ru } & \text { "meu" } \\ 2 & \text { gwa- } & & \text { "teu" } \\ 3 & \varepsilon- & \text { "dele" } \\ 1 d & \text { gi- } & & \text { "nosso" }(1+2) \\ 1 \mathrm{p} & \text { hadji- } & \text { "nosso" }(1+3+(2)) \\ 3 p & \text { bi- } & \text { "deles" }\end{array}$

O sufixo de primeira pessoa tem ainda dois alomorfes, '-ju' e '-jo', que ocorrem com alguns temas em flutuação com '-ru'.

Exemplos:

(1)

(2)

$\begin{array}{lll}\text { a- } \quad \text { tága } & \text {-ru } \\ \text { a- } \quad \text { tága } & -j u \\ 1-\quad \text { nariz } & -1 \\ \text { "meu nariz" } & \\ \text { a- tóra } & - \text { ru } \\ \text { 1- filho } & -1 \\ \text { "meu filho" } & \\ \text { gwa- } & \text { gí } \\ \text { 2- } & \\ \text { "tua mãe" } & \end{array}$


(4)

$\varepsilon-\quad$ pó

3- braço

"braço dele"

(5)

gi- óvi

ld- casa

"nossa casa"

(6) hadzi-róga

1p- joelho

"nossos joelhos"

(7) bi- re

$3 \mathrm{p}$ - olho

"olhos deles"

\section{Flexão verbal}

A flexão pessoal dos verbos apresenta grande complexidade. Ela realiza-se por prefixos e sufixos obedecendo a diferentes padrões.

A flexão dos verbos transitivos, para o caso nominativo, de sujeito, obedece ao seguinte esquema:

\section{Tabela 3}

$\begin{array}{lll}\text { Pessoa } & \text { Prefixo } & \begin{array}{l}\text { Sufixo } \\ \text {-jo }\end{array} \\ 1 & \text { gwa- } & \\ 2 & \varepsilon- & \\ 3 & \text { ga- } & \\ 1 d & \text { dza } & \\ 1 p & \text { be } & \\ 3 p & \end{array}$

Alguns exemplos podem mostrar essas realizações:

(8)

na- ro -jo g- égĩtí

ind- comer -1 det- peixe

"como peixe"

(9)

$n-\varepsilon$ - ro go- ri

ind-3- comer det- carne

"ele come carne" 
Os verbos intransitivos, os descritivos². e o caso objetivo dos verbos transitivos no singular flexionam-se de acordo com o seguinte padrão:

\section{Tabela 4}

$\begin{array}{lll}\text { Pessoa } & \text { Prefixos } & \text { Sufixos } \\ 1 & & - \text { jo } \\ 2 & & \text {-he } \\ 3 & & \text { o }\end{array}$

$1 d$

$1 \mathrm{p}$

$3 p$

ga-

dza-

be

Os exemplos mostram esse comportamento:

na- be- kini

ind- $3 p-$ dormir

"eles dormem"

(11)

$\begin{array}{ll}\text { n- ákwo } & \text {-he } \\ \text { ind- branco } & -2 \\ \text { "tu és branco" } & \end{array}$

O caso objetivo dos verbos transitivos flexionam-se no plural de acordo com o seguinte esquema:

\section{Tabela 5}

$\begin{array}{ll}\text { Pessoa } & \text { Prefixos } \\ 1 \mathrm{~d} & \mathrm{~g} \varepsilon- \\ 1 \mathrm{p} & \mathrm{d} z \varepsilon- \\ 3 \mathrm{p} & \emptyset\end{array}$

Os seguintes exemplos mostram essas realizações:

$$
\begin{aligned}
& \text { na- } \varepsilon \text { - ge- bagáki } \\
& \text { ind- } 3 \text { - } 1 \mathrm{~d} \text { bater } \\
& \text { "ele bate em nós dois" }
\end{aligned}
$$

\footnotetext{
2 Os verbos descritivos correspondem aproximadamente às noções dos adjetivos em português e são conjugados como os verbos intransitivos.
} 
(13)

na- be- bagáki -he

ind- $3 p-$ bater -2

"eles batem em você"

(14)

na- gwa- dze- bagáki

ind- 2- $1 \mathrm{p}-$ bater

"você bate em nós todos"

Em uma tabela reunindo todas essas flexões pode-se visualizar o comportamento geral dos marcadores pessoais nesta língua:

\section{Tabela 6}

\begin{tabular}{|l|l|l|l|l|l|}
\hline Pessoas & Pronomes & Nomes & Suj.Vtr & Suj Vi/des & Objeto \\
\hline 1 & -jo & a- -ru & -jo & -jo & -jo \\
\hline 2 & -he & gwa- & gwa- & -he & -he \\
\hline 3 & & $\varepsilon-$ & $\varepsilon-$ & o & o \\
\hline ld & gi- & gi- & ga- & ga- & ge- \\
\hline lp & hadzi- & hadzi & dza- & dza- & dze- \\
\hline $3 p$ & & bi- & be- & be- & o \\
\hline
\end{tabular}

A língua Guató apresenta três padrões para manifestar a flexão pessoal: um padrão para a primeira pessoa do singular, uma neutralização entre sistemas; outro padrão para a segunda e terceira pessoas do singular, um sistema ergativo /absolutivo, que ressalta as noções agente/paciente; e um terceiro padrão para as pessoas dual e plural, um sistema nominativo/acusativo, como em português. São três padrões distintos para representar um sistema tripartido. Embora essas manifestações sejam expressas através de marcas puramente morfológicas, pode-se afirmar que se trata de uma língua cindida, que se divide no uso de sistemas, mas que também apresenta uma divisão sui generis, pois se subdivide en dois padròes para o singular em oposição a um terceiro para o plural. 


\section{REFERÊNCIAS BIBLIOGRÁFICAS}

COMRIE, B. Ergativity. In: LEHMANN, W. P. (ed.). Syntactic Typology: Studies in the phenomenology of language. Austin: University of Texas Press, 1978, 7:329-394.

COMRIE, B. Language Universals and Linguistic Typology: Syntax and Morphology. Chicago: The University of Chicago Press, 1981.

DIXON, R. M.W. Ergativity, Language, vol.55.1:59-138, 1979.

GARDE, P. L'Accent. Vol.5. Le Linguiste. Paris: Presses Universitaires de France, 1968.

GREENBERG, J. H. (ed). Universals of Language. 2 ed. Cambridge, Mass.: MIT Press, 1966a.

GREENBERG, J. H. (ed). Universals of Language. 2 ed. Cambridge, Mass.: MIT Press, 1966b. Some universals of grammar with particular reference to the order of meaningful elements. 73-113.

JAKOBSON, R., GUNNAR C., FANT, M.e HALLE, M. Preliminaries to speech analysis: the distinctive features and their. correlates. Cambridge, Mass.:MIT Press, 1973.

JAKOBSON, R.; HALLE, M. Fundamentals of Language. 2 ed. The Hague: Mouton, 1975.

LEHMANN, W. P. (ed.). Syntactic Typology: Studies in the phenomenology of language. Austin: University of Texas Press, 1978.

PALÁCIO, A. P. Guató, a língua dos indios canoeiros do rio Paraguai. Tese de Doutorado. Campinas: Universidade Estadual de Campinas, IEL, 1984.

PIKE, K. L. Tone Languages. Ann Arbor: The University of Michigan Press, 1948.

RODRIGUES, A. D. Tarefas da Lingüística no Brasil. Estudos Lingüisticos, vol.1 1:4-15, 1966.

RODRIGUES, A. D. Linguas brasileiras: para o conhecimento das linguas indigenas.São Paulo: Loyola, 1986.

SCHMIDT, M. Estudos de etnologia brasileira. Trad. Catarina B. Cannabrava. Brasiliana, Gr. Formato, vol. 2. São Paulo: Cia. Ed. Nacional, 1942. 